\title{
Hambúrguer de peixe: Transferência tecnológica e seu impacto na renda dos participantes
}

\author{
Lílian Carla Neves Serrão ${ }^{1}$, Hérlon Mota Atayde²
}

\begin{abstract}
Resumo: A transferência tecnológica é um processo de difusão de conhecimentos que envolve partes receptoras e emissoras de determinado conjunto de técnicas. Nesse artigo é apresentada a transferência tecnológica adotada em um projeto extensionista da Universidade Federal do Oeste do Pará (UFOPA), sobre a produção e comercialização do hambúrguer de peixe. Adicionalmente, foi verificada a influência dessa transferência na obtenção de renda pelos participantes. Para a transferência, após pesquisa bibliográfica pelo discente bolsista, roda de conversa com o orientador, foram realizadas pelo discente, práticas de preparo, elaboração de material de divulgação e de apoio didático e avaliativo. Foram ministrados cursos teóricopráticos sobre a escolha da matéria-prima, e o preparo e a comercialização do hambúrguer de peixe. A participação nesses cursos foi voluntária, com taxa simbólica de matrícula, sem preferência por público-alvo. Ao final de cada curso, cada participante preencheu um questionário avaliativo do curso ministrado. Onze meses depois, foram quantificados os participantes que fizeram uso posterior dessa tecnologia, assim como sua finalidade. No geral, apenas 35 (50,7\%) dos inscritos efetivamente participaram dos cursos, os quais apontaram $99 \%$ de satisfação. Desses participantes, $48,6 \%$ fizeram uso posterior da técnica e consideraram sua execução satisfatória. Entretanto, somente 8,6\% (n=3) o fez com finalidade de geração de renda complementar e se declarou totalmente satisfeito com a venda. Constatou-se o sucesso da transferência tecnológica, mas a efetividade dessa transferência na geração de renda complementar dos participantes foi baixa, mesmo se constatando o lucro satisfatório.
\end{abstract}

Palavras-chave: Tecnologia do Pescado; Fishburguer; Capacitação

\section{Fish hamburger: Transfer of technology and its impact on participants' income}

Abstract: Transfer of technology is a process of knowledge diffusion that involves receivers and emitters of a given set of techniques. This article presents the technology transfer adopted in an extension project of the Federal University of Western Pará (UFOPA), on the production and marketing of fish hamburgers. Additionally, the influence of this transfer on participants' income was verified. After a bibliographic search, the undergraduate student attended conversations with the advisor and carried out the preparation of practices and support material for dissemination, didactic, and evaluative purposes. Theoretical and practical courses on how to select and prepare raw material for the fish hamburger, and marketing classes, were given along the transfer process. Participation in these courses was voluntary, with a symbolic registration fee, with no target audience preference. At the end of each course, each participant completed an assessment questionnaire. Eleven months later, the participants who later used the technology and how they used it were quantified. Overall, only $35(50.7 \%)$ of the registered participants participated in the courses, which indicated $99 \%$ satisfaction. Of these participants, $48.6 \%$ used the technique and found it satisfactory. However, only $8.6 \%(n=3)$ did it with the purpose of generating supplementary income, and were totally satisfied. The transfer of technology was considered successful, but its effectiveness in the participants' complementary income generation was low, even though there was a satisfactory profit.

Keywords: Aquafood Technology; Fish Burger; Training Course
Originais recebidos em

14 de outubro de 2019

Aceito para publicação em

27 de março de 2020

1

Engenheira de Pesca formada pelo Instituto de Ciências e Tecnologia das Águas (ICTA) da Universidade Federal do Oeste do Pará (UFOPA)

2 Docente do Instituto de Ciências e Tecnologia das Águas ICTA/UFOPA

Rua Vera Paz, s/n, Unidade Tapajós, Bloco Modular, sala 404, Bairro Salé, CEP 68040-255, Santarém, Pará, Brasil.

herlon.atayde@ufopa.edu.br (autor para correspondência) 


\section{Introdução}

O consumo de peixe no Brasil, principalmente fresco ou resfriado, ganha mais adeptos ao longo dos anos devido as suas características nutricionais, mas a predominância de exemplares com fatores interferentes para o consumo (muitas espinhas intramusculares, sem escamas, aspecto morfológico considerado feio, tabus alimentares regionais, entre outros) e o baixo nível de processamento (majoritariamente in natura), suscitam a necessidade de inovação do produto a ser ofertado para o consumidor (Braga et al., 2016; Lopes et al., 2016; Larrea-Killinger et al., 2019).

Neste contexto, uma das formas de diferenciação e inovação para o consumo é a elaboração do hambúrguer de peixe (ou fishburguer, na escrita aportuguesada), um derivado com elevado teor proteico, estabilidade lipídica e boa aceitação sensorial (Furtado Jr., 2016; Raúl et al., 2018).

Como a matéria-prima destes derivados é basicamente a mesma, o que se diferencia no seu preparo é geralmente a adição de condimentos, uma vez que a utilização daqueles mais acessíveis e de uso comum na cozinha doméstica pode promover a comercialização por pequenos empreendedores, os quais ofertarão produtos de origem animal com um ótimo nível proteico e alto valor agregado (Amaral et al., 2016; Duran et al., 2017).

Considerando que a cidade de Santarém - Pará possui grande oferta de pescado, torna-se inovador que a comunidade receba qualificação especializada em Tecnologia do Pescado. Conforme Rocha-Vidigal \& Vidigal (2012), isso constitui uma das formas de investimento em capital humano, porque permite ao trabalhador aprimorar suas habilidades e sua produtividade.

Nesse relato é apresentada a transferência de tecnologia para a produção e comercialização do hambúrguer de peixe, e sua influência no desenvolvimento de uma atividade laboral para fins de geração de renda pelos participantes de uma atividade extensionista.

\section{Procedimentos metodológicos}

Nessa publicação estão contempladas as ações desenvolvidas no último ano de vigência do projeto 'Triturados de Pescado Amazônico - Uma Alternativa de Renda e Consumo', parte do Programa de Atenção, Integração e Extensão em Recursos Aquáticos, Aquicultura e Tecnologias Aplicadas do Bacharelado em Engenharia de Pesca (PAIEEP) da Universidade Federal do Oeste do Pará (UFOPA), período 2015-2017, suplementadas com informações obtidas em 2018.

\section{Aspectos gerais do projeto de extensão}

Na primeira etapa desse projeto, as atividades foram efetuadas na forma de pesquisa bibliográfica pela discente bolsista dessa atividade extensionista e roda de conversa com o coordenador, abordando temas como características físico-químicas, nutricionais, microbiologia e parasitologia do pescado e seus produtos, produção artesanal, avaliação sensorial e aspectos econômicos da produção de pasta de pescado e seus derivados.

Em seguida, foram efetuadas as seguintes ações:

a) a reformulação do fishburguer elaborado na primeira fase desse projeto (Vieira et al. 2016), retirando a farinha de avium (Acetes spp.), sem substituição, pois, além de motivos religiosos (como exemplo, segmento cristão adventista), Braga et al. (2016) e Lopes et al. (2019) citam que alguns amazônidas consideram o consumo de crustáceos capaz de agravar processos infecciosos. 
b) um estudo mais detalhado sobre a técnica de preparação do fishburguer, com práticas de preparo e degustação do mesmo;

c) elaboração do material a ser utilizado para divulgação por meio de mídias digitais (mensagens eletrônicas diretamente enviadas para representantes de associações comunitárias ou estudantis, ou por Facebook, Instagram, Whatsapp, entre outros) e pôsteres afixados em diversos locais (universidades, centros comunitários, igrejas, entre outros), e elaboração de materiais de apoio (didático e avaliativo) utilizados na próxima etapa.

Na segunda etapa, foram ministrados os cursos de capacitação sobre a preparação e comercialização de fishburguer para participantes voluntários, com turmas mistas quanto à área de atuação profissional. Os cursos $(C)$ (carga horária $=10 \mathrm{~h}$ ) e respectivas datas, com limite de vagas para 15 participantes/turma foram ministrados no Laboratório Multidisciplinar de Recursos Aquáticos da UFOPA (C1 e C2), Paróquia do Santíssimo Sacramento (C3 e C4) e residência de Maria Rosinete Neves Serrão (C5). O horário das aulas foi de $7 \mathrm{~h} 30$ as $12 \mathrm{~h} 30$ (duas manhãs), com exceção do C5 que foi realizado de $8 \mathrm{~h}$ as $19 \mathrm{~h}$, com intervalo para almoço.

\section{Aquisição e seleção da matéria prima (peixe)}

A aquisição da matéria-prima para os cursos C1, C2, C3 e C4 foi efetivada no Mercadão 2000, uma das feiras de comercialização de pescado em Santarém - Pará. A seleção do peixe fresco foi efetuada por avaliação sensorial, utilizando os critérios de qualidade para pescado fresco contidos na legislação vigente (Ministério da Agricultura Pecuária e Abastecimento, 2017). Os peixes selecionados foram depositados em isopor (adicionando-se gelo tipo escama, para manutenção das características sensoriais) e transportados para os locais dos cursos de capacitação.

No último curso (C5), os peixes foram capturados e doados por um dos participantes, sendo mantidos sob refrigeração até a realização do curso, quando foram selecionados conforme o frescor.

\section{Elaboração do fishburguer}

No espaço onde o curso foi realizado, as vísceras foram retiradas com auxílio de facas e tábuas de cortar. Em seguida foi efetuada a retirada de pele, separando-a do filé (Figura 1). Finalizadas essas operações, o filé foi lavado para retirada de escamas residuais e outras sujidades.

Similar ao descrito por Caldas et al. (2018), os filés sem pele dos peixes foram triturados em moinho manual (Figura 2A). Esse triturado foi lavado com água gelada suplementada com hipoclorito de sódio, na proporção de 1,0 ml/5 litros de água, durante 10 a 15 minutos. Em seguida, foi retirado o excesso de água por meio de filtração e prensagem da carne, utilizando como elemento filtrante um saco de pano previamente higienizado (Figura 2B). A massa retida foi denominada pasta de pescado.

Todos os ingredientes (incluindo a pasta de pescado) foram pesados em balança digital e homogeneizados em bandeja plástica, cuja mistura foi separada em partes iguais ( $80 \mathrm{~g}$ cada) e moldadas em formato circular, entre filmes plásticos, sendo denominada fishburguer (Figura 3). Para armazenamento, indicou-se o uso da unidade congeladora das geladeiras domésticas ou de freezers, pelo tempo máximo de trinta dias. 


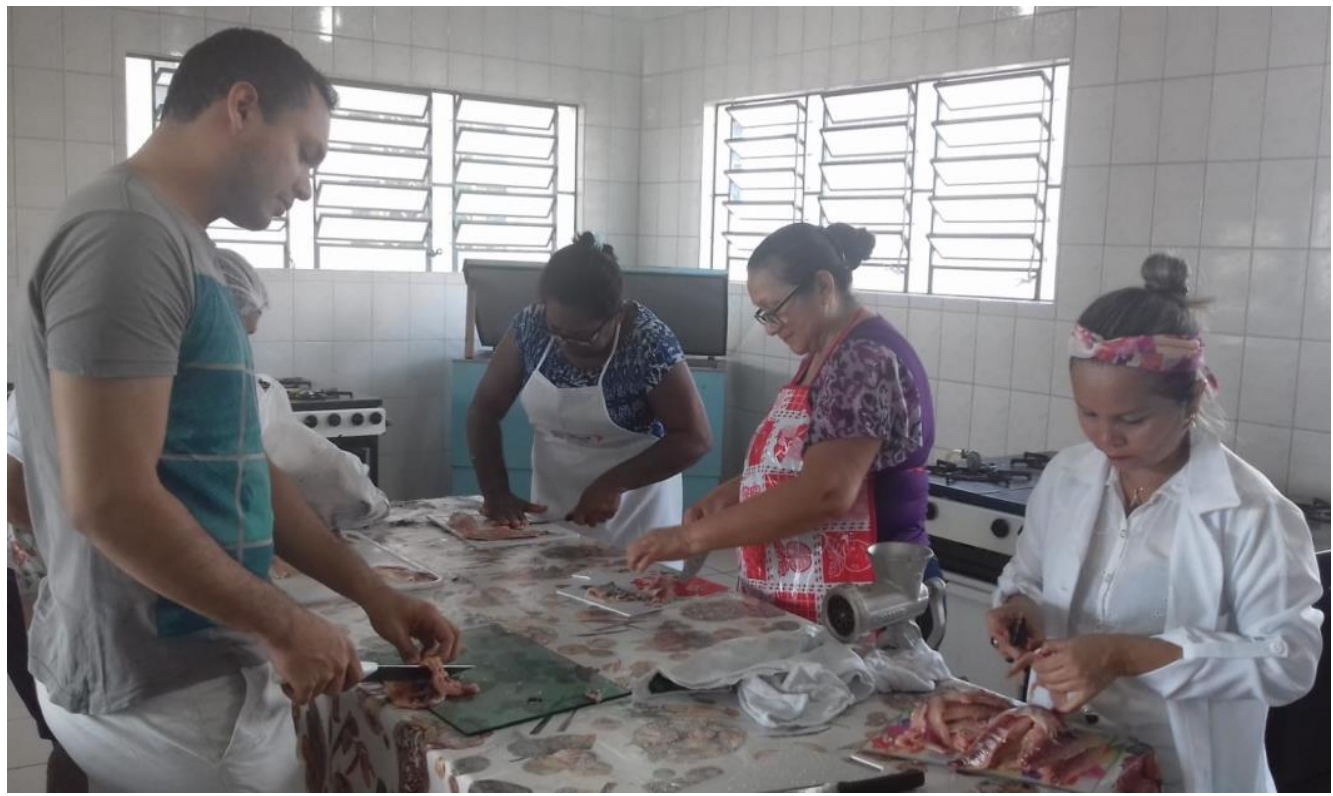

Figura 1. Participantes extraindo o filé sem pele dos peixes selecionados.

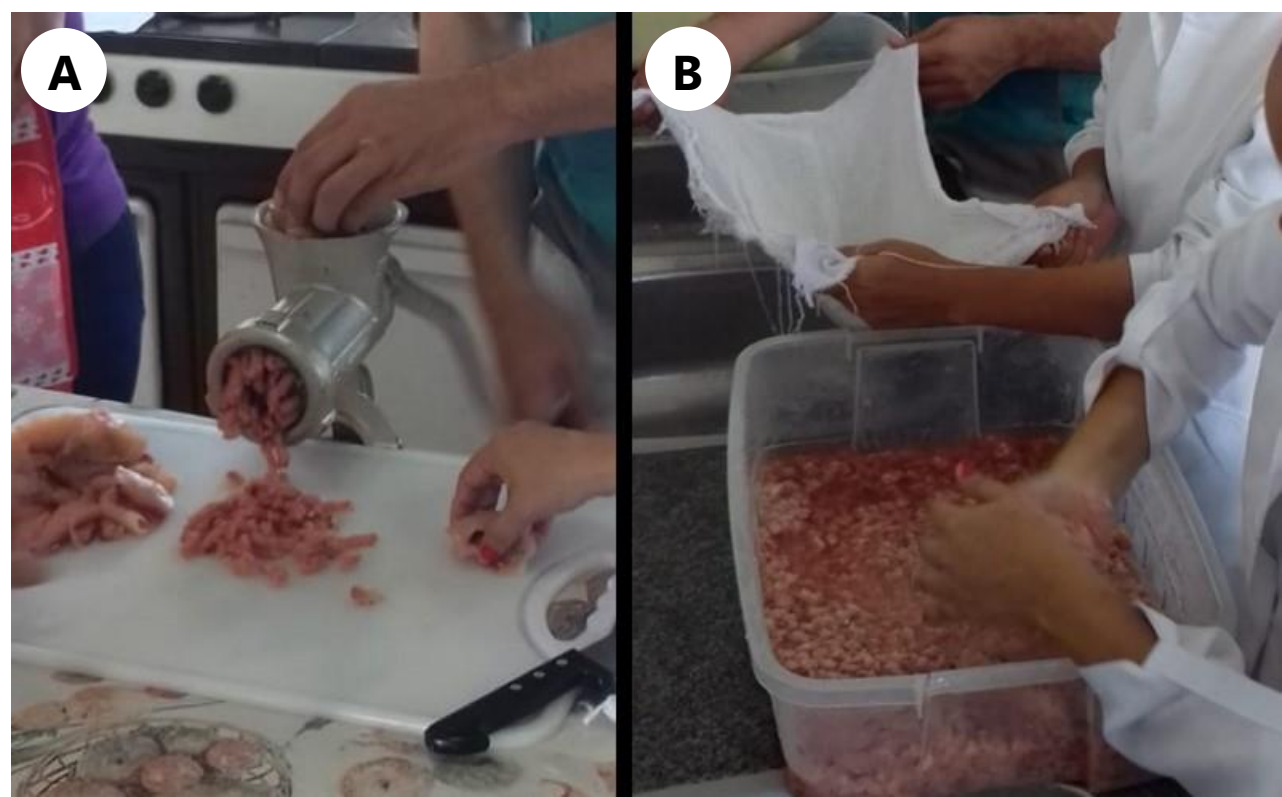

Figura 2. Moagem (A) e preparo do triturado para a drenagem (B).

\section{Estabelecimento do custo mínimo dos fishburgueres}

Aos participantes, por intermédio de exposição oral acompanhada de demonstração escrita, foi apresentado o modo como fariam a estimativa de custo mínimo do produto, similar ao utilizado por Silva et al. (2017), conforme fórmula a seguir.

$$
\text { Custo por ingrediente }=\frac{(Q t d e . \text { utilizada } \times \text { Valor comercial })}{\text { Qtde. } \text { da porção comercial }}
$$




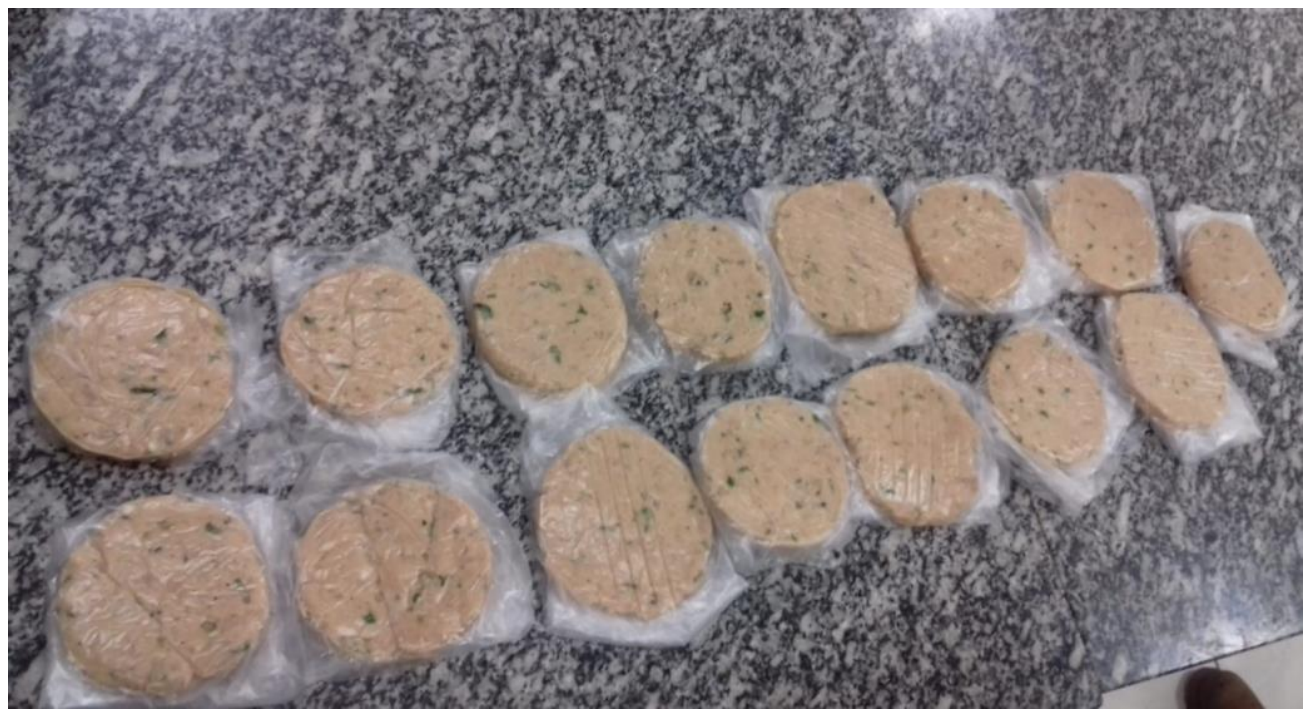

Figura 3. Fishburgueres crus já formatados e preparados para o congelamento.

\section{Cálculo das perdas associadas ao processamento dos fishburgueres}

Para sensibilizar os participantes quanto ao rigor da pesagem no momento da formatação, de forma a evitar perdas importantes para o seu negócio, foram comparados os quantitativos de fishburgueres obtido ( $\mathrm{Nfb}$ obtido, por contagem simples) e o esperado ( $\mathrm{Nfb}$ esperado) pelo cálculo do índice de perdas (fórmula abaixo).

$$
\text { Perdas }(\text { em } \%)=\frac{(\mathrm{Nfb} \text { esperado }-\mathrm{Nfb} \text { obtido })}{\mathrm{Nfb} \text { esperado }} \times 100
$$

\section{Verificação das expectativas e impactos dos cursos no cotidiano dos participantes}

Ao final de cada curso, os participantes registraram suas expectativas e impressões em relação ao curso ministrado respondendo as seguintes questões contidas em questionário: "Os objetivos foram apresentados pela ministrante?"; "Os meus objetivos com o curso foram alcançados?"; "A metodologia utilizada nas aulas facilitou meu aprendizado?"; "O tempo das aulas foi muito longo?"; "O tempo das aulas foi muito curto?"; "O ambiente/espaço utilizado para as aulas foi adequado?"; "Minha relação com a ministrante foi amigável?"; "Gostei da metodologia utilizada pela ministrante?", "A ministrante transmitiu bem o conteúdo das aulas?"; "A ministrante tinha domínio do conteúdo que ensinou?". Todas admitiam como resposta as seguintes alternativas: "sim", "a maioria das vezes", "poucas vezes" ou "não". Em seguida, preparou-se o fishburguer para degustação, utilizando pão, queijo muçarela, tomate vermelho e alface crespa (Figura 4).

Onze meses após a finalização do último curso, todos os participantes foram entrevistados mediante ligação telefônica, seguindo formulário pré-estabelecido para verificação do impacto gerado pelo conhecimento adquirido no curso em seu cotidiano, quando responderam "Você usou as orientações do curso e fez seu fishburguer?". Para respostas negativas: "Por que não?", e para positivas: "Quantas vezes?", "Mudou algum ingrediente?", "Você fez ou está fazendo para consumo próprio (no máximo familiares e amigos próximos) ou para vender?", "Qual o valor cobrado?" (para respostas para vender), "O lucro obtido foi medianamente ou completamente satisfatório?", "Qual o menor valor seria suficiente para você considerar esse lucro totalmente satisfatório?" (para respostas medianamente satisfatório) e "Em relação à aparência, sabor e odor, você ficou satisfeito (a) com seu fishburguer?". 


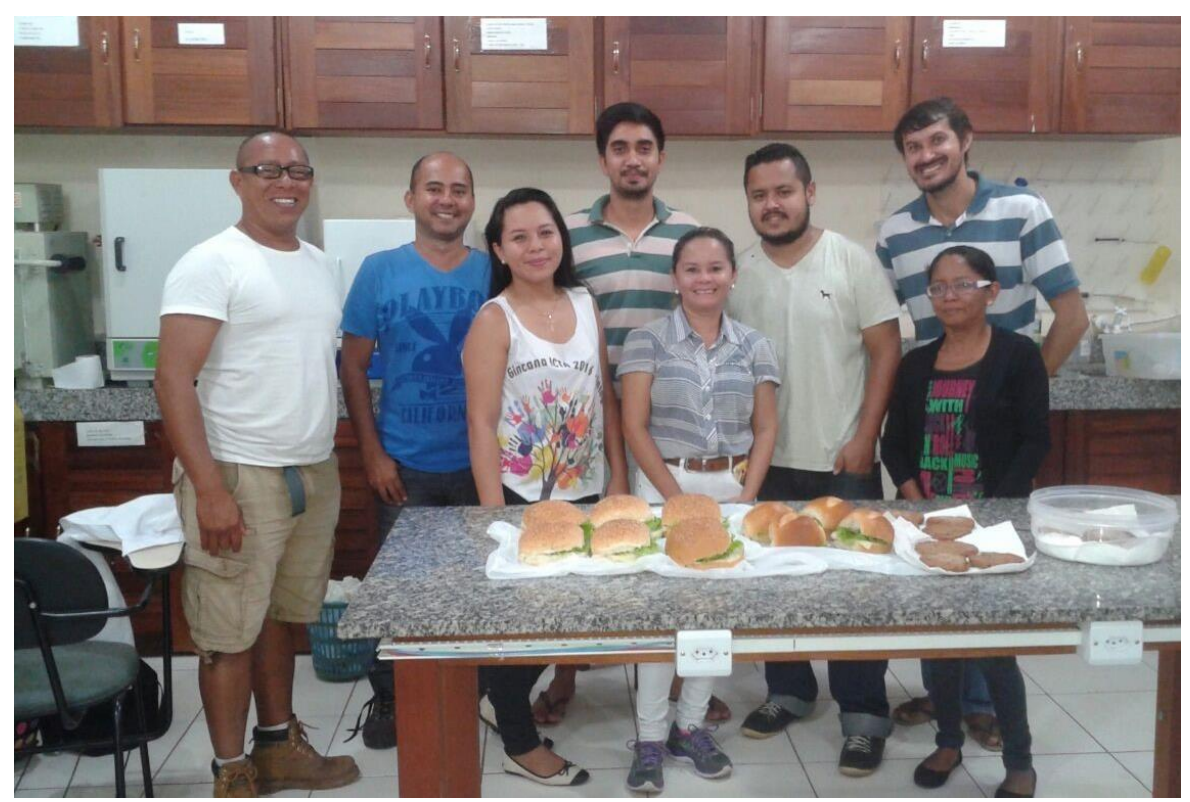

Figura 4. Momento prévio à degustação dos fishburgueres.

\section{Análises estatísticas}

Todas as respostas obtidas em cada sondagem (aplicação de questionário e entrevista) foram analisadas (principalmente as observações inseridas voluntariamente pelos participantes), sendo algumas transformadas em valores absolutos e organizadas em planilha eletrônica. Posteriormente, foram submetidas a análise estatística descritiva e comparativa, esta última ao nível de $5 \%$ de significância, utilizando o software Minitab versão 19.1.1. Como exemplo, foi aplicado o teste Qui-quadrado para verificar a existência de diferenças estatisticamente significativas entre as quantidades produzida e esperada; quantidade esperada e o índice de perda de fishburgueres de cada curso; número de participantes esperados e efetivos em cada curso.

\section{Resultados}

Foram realizados cinco cursos práticos de capacitação (C) sobre o preparo dos fishburgueres, em três locais diferentes e utilizando diversos tipos de peixes e outros itens, conforme Tabela 1, na qual consta a estimativa do custo mínimo da produção de fishburguer em cada um deles. No último curso (C5), uma residência particular foi gentilmente cedida por uma participante da associação de bairro requisitante do curso, por ser um lugar amplo, apropriado para manipulação de alimentos e mais próximo para todos os interessados.

Entre os 35 participantes, 13 eram acadêmicos da UFOPA e 22 eram membros da sociedade civil organizada (associação de moradores de bairro, associações religiosas ou empresários do setor alimentício). Todos foram orientados a executar técnicas de processamento do pescado (evisceração, retirada da pele e extração do filé), preparo da pasta e formulação (adição de ingredientes) e preparo do fishburguer (mistura, moldagem e embalagem). 
Tabela 1. Custos de preparação de fishburguers, por curso.

\begin{tabular}{|c|c|c|c|c|c|c|c|c|c|c|}
\hline \multirow[b]{2}{*}{ Ingredientes } & \multicolumn{10}{|c|}{ Cursos ministrados e respectivos locais } \\
\hline & \multicolumn{2}{|c|}{$\begin{array}{c}\text { C1 } \\
\text { LEMRA/UFOPA }\end{array}$} & \multicolumn{2}{|c|}{$\begin{array}{c}\text { C2 } \\
\text { LEMRA/UFOPA }\end{array}$} & \multicolumn{2}{|c|}{$\begin{array}{c}\text { C3 } \\
\text { Cozinha paroquial }\end{array}$} & Cozin & oquial & Resid & ticular \\
\hline Peixes utilizados & \multicolumn{2}{|c|}{$\begin{array}{l}\text { Matrinxã } \\
\text { (Brycon amazonicus) }\end{array}$} & \multicolumn{2}{|c|}{$\begin{array}{l}\text { Jaraqui } \\
\text { (Semaprochilodus sp.) } \\
\text { Pescada } \\
\text { (Plagioscion spp.) }\end{array}$} & \multicolumn{2}{|c|}{$\begin{array}{l}\text { Jaraqui } \\
\text { (Semaprochilodus sp.) }\end{array}$} & \multicolumn{2}{|c|}{$\begin{array}{l}\text { Jaraqui } \\
\text { (Semaprochilodus sp.) }\end{array}$} & \multicolumn{2}{|c|}{$\begin{array}{l}\text { Pacu (Mylossoma spp.), } \\
\text { Jaraqui (Semaprochilodus sp.) } \\
\text { Pescada (Plagioscion spp.) } \\
\text { Aracu (Leporinus friderici). }\end{array}$} \\
\hline \multirow{3}{*}{$\begin{array}{l}\text { Rendimento de pasta de pescado } \\
\text { (em g) }\end{array}$} & \multicolumn{2}{|c|}{2.811} & \multicolumn{2}{|c|}{678} & \multicolumn{2}{|c|}{1.500} & \multicolumn{2}{|c|}{3.842} & \multicolumn{2}{|c|}{4.805} \\
\hline & \multicolumn{10}{|c|}{ Custos (em R\$) } \\
\hline & PC & PU & PC & PU & PC & PU & PC & PU & PC & PU \\
\hline Custo do peixe $=$ custo da pasta & 197,00 & 197,00 & 75,00 & 75,00 & 40,00 & 40,00 & 60,00 & 60,00 & 50,00 & 50,00 \\
\hline Gordura vegetal & 9,00 & 5,66 & 9,00 & 1,22 & 9,00 & 2,70 & 9,00 & 6,75 & 9,00 & 6,75 \\
\hline $\begin{array}{l}\text { Cebolinha verde e chicória } \\
\text { (mistura) }\end{array}$ & 1,00 & 0,16 & 1,00 & 0,05 & 1,00 & 0,07 & 1,00 & 0,20 & 1,00 & 0,22 \\
\hline Coentro & 0,50 & 0,16 & 0,50 & 0,02 & 0,50 & 0,07 & 0,50 & 0,20 & 0,50 & 0,17 \\
\hline Cebola & 2,50 & 0,81 & 1,50 & 0,07 & 0,50 & 0,35 & 2,00 & 1,04 & 2,50 & 0,78 \\
\hline Pimentinha & 1,60 & 1,63 & 2,00 & 0,60 & 3,00 & 0,87 & 3,50 & 2,08 & 2,00 & 1,56 \\
\hline Pimenta do reino com cominho & 2,50 & 0,31 & 2,50 & 0,10 & 2,50 & 0,13 & 2,50 & 0,40 & 2,50 & 0,33 \\
\hline Tempero industrial & 2,15 & 2,02 & 2,15 & 0,43 & 2,15 & 0,43 & 2,79 & 2,58 & 2,15 & 1,29 \\
\hline Sal & 1,19 & 0,19 & 1,19 & 0,04 & 1,19 & 0,04 & 1,19 & 0,24 & 1,19 & 0,08 \\
\hline Alho & 7,99 & 0,97 & 2,55 & 0,14 & 2,55 & 0,31 & 2,80 & 1,24 & 2,80 & 0,52 \\
\hline Amido de milho & 1,99 & 0,51 & 1,99 & 0,16 & 1,99 & 0,19 & 1,99 & 0,64 & 1,99 & 0,51 \\
\hline Gelo & 12,00 & 12,00 & 6,00 & 6,00 & 6,00 & 6,00 & 6,00 & 12,00 & 6,00 & 12,00 \\
\hline Saco de pano & 10,00 & 10,00 & 2,50 & 2,50 & 2,50 & 5,00 & 5,00 & 5,00 & 2,50 & 5,00 \\
\hline Saco plástico & 2,50 & 0,89 & 2,50 & 0,28 & 2,50 & 0,50 & 2,50 & 1,20 & 2,50 & 0,50 \\
\hline Total por quantidade & 232,3 & 35 und & 86, & 1 und & 56,6 & und & 93, & und & & \\
\hline Custo por unidade (em R\$) & & & 7,90 & & 2,83 & & & & & \\
\hline
\end{tabular}

Legenda: LEMRA = Laboratório de Ensino Multidisciplinar em Recursos Aquáticos; PC= Porção comercial; PU= Porção utilizada. 
A variação dos custos mínimos de produção (Tabela 1) foi influenciada pelo valor comercial do peixe utilizado e as perdas devido à falta de frescor em alguns exemplares adquiridos.

Enfatizou-se que as perdas no processo de produção (Tabela 2) foram consequência da desatenção na pesagem e isso pode afetar a lucratividade do empreendimento, pois predominaram fishburgueres com peso maior que 80 gramas.

A respeito da análise dos cursos pelos participantes, constatou-se grande satisfação ( $99 \%$, Tabela 3), e somente o tempo de duração deles foi criticado.

Nas consultas efetuadas 11 meses após a conclusão do último curso (Tabela 4), foi verificado que praticamente metade dos participantes continuaram preparando o fishburguer, majoritariamente com objetivo de lazer, mas todos ficaram satisfeitos com o resultado obtido. Poucos fizeram uso de ingredientes diferentes daqueles utilizados nos cursos.

Tabela 2. Produção estimada, obtida, e índice de perda dos fishburgueres.

\begin{tabular}{|c|c|c|c|c|c|}
\hline \multirow{2}{*}{ Fishburguers } & \multicolumn{5}{|c|}{ Cursos ministrados } \\
\hline & $\mathrm{C1}$ & C2 & C3 & C4 & C5 \\
\hline Produção esperada* & 49 & 11 & 24 & 65 & 60 \\
\hline Produção obtida* & 35 & 11 & 20 & 48 & 45 \\
\hline Índice de perda (em \%) & 28,6 & 0 & 16,7 & 26,2 & 19,4 \\
\hline
\end{tabular}

Legenda: * em unidades de $80 \mathrm{~g} ;{ }^{*}$ em kg

Tabela 3. Satisfação dos participantes em relação ao curso.

\begin{tabular}{lcc}
\hline \multirow{2}{*}{ Resumo dos questionamentos aplicados aos participantes } & \multicolumn{2}{c}{ Grau de Satisfação } \\
\cline { 2 - 3 } & Positiva & Negativa \\
\hline Objetivos alcançados & $100 \%$ & $0 \%$ \\
\hline Metodologia Adequada & $100 \%$ & $0 \%$ \\
\hline Tempo adequado & $95 \%$ & $5 \%$ \\
\hline Interação capacitadora/capacitandos amigável & $100 \%$ & $0 \%$ \\
\hline Domínio do assunto pela capacitadora & $100 \%$ & $0 \%$ \\
\hline Média & $99 \%$ & $1 \%$ \\
\hline
\end{tabular}


Tabela 4. Satisfação e utilização da técnica de produção de fishburguer, de forma autônoma, onze meses após o último curso ofertado.

\begin{tabular}{|c|c|c|c|}
\hline \multirow{2}{*}{$\begin{array}{l}\text { Síntese das questões apresentadas aos } \\
\text { participantes }\end{array}$} & \multicolumn{3}{|c|}{ Respostas obtidas (\%) } \\
\hline & $\begin{array}{l}\operatorname{Sim} \\
17(48,6 \%)\end{array}$ & & $\begin{array}{l}\text { Não } \\
18(51,4 \%)\end{array}$ \\
\hline Efetuou mudança na formulação?* & $\begin{array}{l}\operatorname{Sim} \\
6(17,1 \%)\end{array}$ & & $\begin{array}{l}\text { Não } \\
11 \text { (31,5\%) }\end{array}$ \\
\hline Finalidade do produto?* & $\begin{array}{l}\text { Lazer } \\
14(40,0 \%)\end{array}$ & $\begin{array}{l}\text { Venda } \\
1(2,9 \%)\end{array}$ & $\begin{array}{l}\text { Lazer/Venda } \\
2(5,7 \%)\end{array}$ \\
\hline Satisfação pessoal com o produto elaborado?* & $\begin{array}{l}\operatorname{Sim} \\
17(48,6 \%)\end{array}$ & & $\begin{array}{l}\text { Não } \\
0 \text { (0\%) }\end{array}$ \\
\hline Se vendeu, qual o valor cobrado?** & $\begin{array}{l}\mathrm{R} \$ 1,00 \text { até } 3,00 \\
2(5,7 \%)\end{array}$ & & $\begin{array}{l}R \$ 3,00 \text { até } 5,00 \\
1(2,9 \%)\end{array}$ \\
\hline Se vendeu, qual a satisfação com o lucro?** & $\begin{array}{l}\text { NS } \\
0(0 \%)\end{array}$ & $\begin{array}{l}\text { MS } \\
0(0 \%)\end{array}$ & $\begin{array}{l}\text { TS } \\
3(8,6 \%)\end{array}$ \\
\hline
\end{tabular}

Legenda: * = Valores em relação aos participantes que responderam Sim para a primeira questão; ${ }^{*}=$ Valores em relação ao somatório dos participantes que efetuaram venda; NS: Não satisfatório; MS: Medianamente satisfatório; TS: Totalmente Satisfatório.

\section{Discussão}

O quantitativo de pessoas interessadas no curso foi diferente da participação efetiva. Apesar do total de inscritos ( $n=69)$, apenas $35(50,7 \%)$ pessoas efetivamente participaram do curso, um quantitativo considerado baixo. Não foi possível obter os motivos do não comparecimento dos faltosos devido a ficha de matrícula não exigir dados para contato, que somente foram coletados entre os participantes efetivos.

A oferta destes cursos buscou promover uma possível opção de renda extra para os participantes por meio dos fishburgueres, principalmente porque a Região Norte, segundo Lopes et al. (2016), é a única do Brasil onde a população possui preferência por peixes em suas refeições.

Pelo uso de produtos de pescado, várias publicações apontam resultados promissores quanto à produção e à aceitação desse produto, especialmente sobre o fishburguer, mesmo que utilizem uma pasta a partir da carne mecanicamente separada, uma técnica diferente daquela utilizada nessa ação extensionista - a filetagem.

Mello et al. (2012) produziram fishburguer a partir do resíduo da filetagem da tilápia-do-Nilo (Oreochromis niloticus) e obtiveram bons resultados, tanto na composição nutricional como na aceitação pelos consumidores. Fogaça et al. (2015) desenvolveram fishburguer de O. niloticus e concluíram que o produto apresentou elevado teor proteico, estabilidade lipídica e boa aceitação sensorial. Portanto, esses pesquisadores demonstraram o potencial de mercado do fishburguer.

Os participantes foram sensibilizados a não negligenciarem a qualidade e o custo de produção, e, nesse último, foi observada maior dificuldade de assimilação. Segundo Gobis e Campanatti (2012), assegurar a qualidade 
implica, entre outros aspectos, em incrementar a competitividade, atratividade, satisfação do cliente e, consequentemente, isso afetará o valor do produto.

O maior custo mínimo correspondeu ao produto do segundo curso, e foi ocasionado pelo menor rendimento em unidades de produto, uma consequência de problemas quanto ao frescor do peixe utilizado. Apesar do preço pago pelos peixes (10 kg de jaraqui [Semaprochilodus spp.] e $5 \mathrm{~kg}$ de pescada [Plagioscion spp.]) não ser o maior entre todos os cursos, parte dessa matéria-prima ( $5 \mathrm{~kg}$ de jaraqui [Semaprochilodus spp.]) não atendia à exigência de qualidade para consumo e, portanto, foi descartado. Esse descarte diminuiu a quantidade esperada de pasta de pescado e encareceu a unidade do fishburguer. Para os participantes, salientou-se a impreterível necessidade de maior rigor na escolha da matéria-prima, resguardando-se assim o lucro a ser obtido.

No primeiro curso, procurou-se utilizar dois exemplares de peixe para que cada participante pudesse praticar as técnicas de retirada de pele e filetagem. Adicionalmente, utilizou-se um peixe já comercialmente bem valorizado, a matrinxã (Brycon cephalus). Esses dois fatores contribuíram para o encarecimento do produto, fato que foi também repassado aos capacitandos como um alerta para que buscassem formas de resguardar seu lucro. Entre as sugestões, mencionou-se que buscassem adquirir um pescado de qualidade, com maior tamanho e volume, com preço mais acessível e com maior rendimento de filé.

Em C5, três dos ingredientes foram doados por um dos participantes, os quais foram informados que, apesar de um ou mais ingredientes serem coletados ou produzidos, é necessário atribuir valor para todos, de acordo com o preço comercial, para que possam estimar o custo mínimo do fishburguer e mensurar um valor para seu trabalho (pesca e/ou coleta). Nesse curso (C5) foi obtido o custo mais baixo ( $R \$ 1,77$ ), ou seja, o uso de ingredientes produzidos/coletados pelo próprio participante pode tornar o seu produto mais competitivo no mercado (considerando a possibilidade de vender mais barato que seu concorrente), ou aumentar sua margem de lucro.

Mesmo que o tipo de peixe utilizado nos cursos tenha variado conforme a oferta no mercado, os participantes foram instruídos a sempre optar pelos peixes mais frescos e com preço mais acessível. Adicionalmente, esses peixes não apresentaram o mesmo rendimento cárneo, mas, como o principal foco da atividade era a transferência de tecnologia, todos foram aproveitados. Essa diferença de rendimento foi salientada durante as explicações porque, considerando que outro principal foco da atividade era incentivá-los a produzir seu fishburguer para comercialização, a escolha da matéria-prima principal era algo de grande relevância.

Quanto às perdas no processo de produção, as diferenças na produção de fishburguer observadas para os cursos $\mathrm{C} 1$, C4 e C5 foram estatisticamente significantes em relação aos demais cursos (teste de $\chi^{2}, p<0,05$ ) e salientam a atenção necessária na pesagem, a qual é relevante se for considerada a venda do produto.

Entre as questões abordadas como menos satisfatórias estava o tempo de duração do curso. Alguns participantes queriam que o curso fosse mais extenso e que fossem abordadas outras formas de se utilizar o pescado, como a linguiça de peixe. Foi explicado que os cursos tratavam da 'preparação de fishburguer', mas que em outra oportunidade esse pedido poderia ser contemplado.

As observações voluntariamente inseridas nos questionários demonstram que os participantes consideraram esses cursos como "muito proveitoso", "com linguagem direta e simples", mas "com dicas importantes na manipulação do peixe e preparo do fishburguer".

Sousa et al. (2018), após realizarem capacitação de pescadores e trabalhadores rurais para trabalhar com derivados de peixes, verificaram uma grande aceitabilidade de aprendizado em relação ao tema estudado. Esses autores apontaram que a oferta de cursos como estes são importantes, pois contribuem na geração de novas oportunidades e alternativas de emprego e renda. 
Apesar da existência de possibilidades da oferta de cursos de capacitação gratuitos ou de baixo investimento pela Universidade para a sociedade civil em geral, se verifica que os órgãos governamentais públicos ainda não apresentam ou propiciam, junto aos financiadores, linhas de crédito e orientação que amparem a sociedade de baixa renda quanto aos pequenos empreendimentos para auxílio em sua renda familiar, conforme constatado nas ponderações de Pedrosa et al. (2013).

Este mesmo interesse econômico já foi avaliado por Di Ciommo (2007), relatando que uma comunidade sem fonte de renda adicional, que recebeu um aporte financeiro por intermédio do trabalho com a pesca e artesanato, manifestou o desejo de conseguir cursos de qualificação e aperfeiçoamento, que lhes permitisse ingressar em novas ocupações, e principalmente beneficiar-se do afluxo de turistas.

Onze meses após o último curso, a transferência de tecnologia dessa ação extensionista pôde ser considerada satisfatória, pois se constatou o uso dos conhecimentos repassados. Esse uso também demonstra o sucesso da metodologia empregada, porque os participantes conseguiram reproduzir com sucesso as operações necessárias, mesmo que não tenham efetuado muitas mudanças de ingredientes. Entre as mudanças, vale destacar a adição de maior quantidade de cebola e pimenta-de-cheiro, tentativa de uso do sumo de limão, e subtração do tempero industrializado, que foi substituído por condimentos recém-triturados.

Quanto ao incremento na renda pelo uso dessa tecnologia, não se obteve um resultado promissor, porque poucos participantes $(n=3)$ transformaram o novo conhecimento em renda complementar, mas estes poucos consideraram satisfatório o lucro dessa iniciativa. Foi também constatada a iniciativa autônoma de dar novas formas à apresentação do fishburguer, modificando-o para um bolinho com formato arredondado e peso de aproximadamente $20 \mathrm{~g}$, ofertado aos clientes como petisco (tira-gosto).

\section{Considerações finais}

Essa ação extensionista foi considerada proveitosa pelos participantes devido à utilização de uma linguagem direta e simples, e por explorar dicas importantes no preparo do fishburguer. Entre as sugestões recebidas, merecem destaque "que mais cursos relacionados ao pescado sejam oferecidos" e "que seja também estabelecido menor prazo para certificação". Os participantes reconhecem que cursos de capacitação nesta área são "de grande importância para toda comunidade, tanto civil quanto acadêmica".

Percebeu-se que o objetivo principal dessa iniciativa extensionista - a utilização posterior dos conhecimentos repassados - foi alcançado, pois alguns participantes fizeram seus fishburgueres, inclusive como complemento de renda, somando os novos conhecimentos adquiridos nos cursos às suas atividades de comércio, lazer e alimentação.

Ressalta-se que um aspecto importante em iniciativas dessa natureza é a escolha de locais com estrutura de cozinha totalmente operacional, pois propicia a degustação do produto e sacia a curiosidade dos participantes ao final do curso. Mesmo com o baixo investimento financeiro pelos inscritos, é necessário compreender os fatores motivadores da baixa participação destes nos cursos, porque, a partir desse conhecimento, diversas medidas poderão ser adotadas, visando diminuir uma possível indiferença quanto aos fishburgueres e correlatos.

\section{Agradecimentos}

Aos participantes, pela gentileza e confiança ao se apresentarem voluntariamente nos cursos dessa ação extensionista. Ao apoio institucional (reconhecimento desse projeto de extensão e concessão de bolsa de 
iniciação à extensão) concedido pela Pró-Reitoria da Cultura, Comunidade e Extensão da Universidade Federal do Oeste do Pará (UFOPA).

\section{Contribuição de cada autor}

Ambos os autores elaboraram e executaram o projeto, e redigiram o texto aqui apresentado. H.M.A. atuou como coordenador dessa ação extensionista.

\section{Referências}

Amaral, M. T., Rodrigues, F. C., de Souza, P. L., \& Jimenez, É. A. (2016). Elaboração e avaliação da aceitabilidade do fishburger de acará-açu (Lobotes surinamensis) no mercado macapaense-AP, Brasil. DEMETRA: Alimentação, Nutrição \& Saúde, 11(4), 965-975.

Braga, T. M. P., da Silva, A. A., \& Rebêlo, G. H. (2016). Preferências e tabus alimentares no consumo de pescado em Santarém, Brasil. Novos Cadernos NAEA, 19(3), 189-204.

Ministério da Agricultura Pecuária e Abastecimento. Brasil. (2017). Decreto no 9.013, de 29 de março de 2017. Diário Oficial da União, S. 1, p. 3. Recuperado de http://www.in.gov.br/materia/-/assetpublisher/Kujrw0TZC2Mb/ content/id/20134722/do1-2017-03-30-decreto-n-9-013-de-29-de-marco-de-2017-20134698

Caldas, K. D. P. P., Santos, P. R. B., \& Atayde, H. M. (2018). Patê de peixe usando resíduos da indústria pesqueira amazônica: Produção e aceitação. Revista Ibero-Americana de Ciências Ambientais, 9(6), 188-198.

Di Ciommo, R. C. (2007). Pescadoras e pescadores: A questão da equidade de gênero em uma reserva extrativista marinha. Ambiente \& Sociedade, 10(1), 151-163.

Duran, N. M., Maciel, E. D. S., Galvão, J. A., Savay-da-Silva, L. K., Sonati, J. G., \& Oetterer, M. (2017). Availability and consumption of fish as convenience food-correlation between market value and nutritional parameters. Food Science and Technology, 37(1), 65-69.

Fogaça, F. D. S., Otani, F. S., Portella, C. D. G., dos Santos-Filho, L. G. A., \& Sant'Ana, L. S. (2015). Caracterização de surimi obtido a partir da carne mecanicamente separada de tilápia do Nilo e elaboração de fishburger. Semina: Ciências Agrárias, 36(2), 765-776.

Furtado Junior, I., Santos, M. D., Tavares, M. C., Matsunaga, A. M., \& Santos, D. C. (2016). "Fishburger" elaborado a partir de peixes do estuário amazônico de baixo valor comercial. Boletim Técnico Científico do CEPNOR, 16(1), 29-35.

Gobis, M. A., \& Campanatti, R. (2012). Os benefícios da aplicação de ferramentas de gestão de qualidade dentro das indústrias do setor alimentício. Hórus, 7(1), 26-40.

Larrea-Killinger, C., De Freitas, M. D. C. S., \& Rêgo, R. D. C. F. (2019). Reima: Proibição de alimentos em comunidades de pescadores na Bahia, Brasil. Revista de Alimentação e Cultura das Américas, 1(1), 46-71.

Lopes, I. G., de Oliveira, R. G., \& Ramos, F. M. (2016). Perfil do consumo de peixes pela população brasileira. Biota Amazônia (Biote Amazonie, Biota Amazonia, Amazonian Biota), 6(2), 62-65.

Lopes, T. M. R., de Brito, A. C. M., Corrêa, C. P., Rocha, D. D. S. A., Caldas, E. M., Martins, J. F. F., ... \& Costa, P. W. N. (2019). Enfermagem, alimentos "reimosos" e o atendimento transcultural a população ribeirinha amazônica: Um relato de experiência. Revista Eletrônica Acervo Científico, 4, e349-e349.

Mello, S. C. R. P., Freitas, M. Q., São Clemente, S. C., Franco, R. M., Nogueira, E. B., \& Freitas, D. D. G. C. (2012). Development and bacteriological, chemical and sensory characterization of fishburgers made of Tilapia minced meat and surimi. Arquivo Brasileiro de Medicina Veterinária e Zootecnia, 64(5), 1389-1397.

Pedrosa, B. M. J., Lira, L., \& Maia, A. L. S. (2013). Pescadores urbanos da zona costeira do estado de Pernambuco, Brasil. Boletim do Instituto de Pesca, 39(2), 93-106. 
Raúl, L. J., Araújo, I. B. D., Barbosa, R. C., Maciel, M. I. S., Shinohara, N. K. S., \& Campagnoli de Oliveira Filho, P. R. (2018). Manufacture of Biquara (Haemulon Plumierii Lacepède, 1801) fishburger with addition of wheat bran. Journal of Aquatic Food Product Technology, 27(5), 544-556.

Rocha-Vidigal, C. B., \& Vidigal, V. G. (2012). Investimento na qualificação profissional: uma abordagem econômica sobre sua importância. Acta Scientiarum. Human and Social Sciences, 34(1), 41-48.

Silva, R. R. M. da, Pires, C. R. F., de Almeida Kato, H. C., de Sousa, D. N., \& dos Santos, V. F. (2017). Pescado na alimentação escolar: Caracterização nutricional. Segurança Alimentar e Nutricional, 24(2), 169-179.

Sousa, D. N. de, de Almeida Kato, H. C., Milagres, C. S. F., \& de Freitas, A. A. (2018). Organização social e produtiva de pescadores para agregação de valor do pescado em mercados institucionais. Revista Brasileira de Engenharia de Pesca, 11(1), 85-96.

Vieira, E. D. L. P., Atayde, H. M., Junior, C. H. F., de Brito, L. S., de Araújo Castro, L., \& Pereira, M. F. (2016). Triturados de pescado amazônico-uma alternativa de renda e consumo. Revista de Extensão da Integração Amazônica, 1(2), 110113.

Como citar este artigo:

Serrão, L. C. N. \& Atayde, H. M. Hambúrguer de peixe: Transferência tecnológica e seu impacto na renda dos participantes. Revista Brasileira de Extensão Universitária, 11(1), 73-85. https://periodicos.uffs.edu.br/index.php RBEU/article/view/11127/pdf 